\title{
Dental health of children with cerebral palsy
}

Basil M. Jan, dental student, Mohammed M. Jan, MB.Ch.B, FRCP(C).

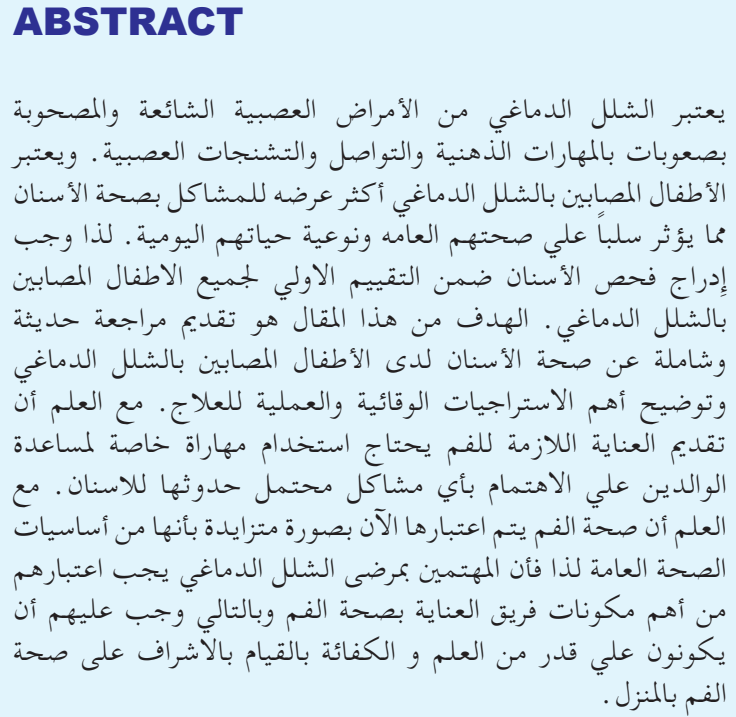

Cerebral palsy (CP) is a common chronic motor disorder with associated cognitive, communicative, and seizure disorders. Children with $\mathrm{CP}$ have a higher risk of dental problems creating significant morbidity that can further affect their wellbeing and negatively impact their quality of life. Screening for dental disease should be part of the initial assessment of any child with CP. The objective of this article is to present an updated overview of dental health issues in children with $\mathrm{CP}$ and outline important preventative and practical strategies to the management of this common comorbidity. Providing adequate oral care requires adaptation of special dental skills to help families manage the ongoing health issues that may arise. As oral health is increasingly recognized as a foundation for general wellbeing, caregivers for CP patients should be considered an important component of the oral health team and must become knowledgeable and competent in home oral health practices.

Neurosciences 2016; Vol. 21 (4): 314-318 doi: 10.17712/nsj.2016.4.20150729

From the Department of Pediatrics, Faculty of Medicine, King Abdulaziz University, Jeddah, Kingdom of Saudi Arabia
Address correspondence and reprint request to: Prof. Mohammed M. Jan, Department of Pediatrics, Faculty of Medicine, King Abdulaziz University, Jeddah, Kingdom of Saudi Arabia. Tel. +996 126401000 Ext.20208.E-mail:mmjan@kau.edu.sa

Cerebral palsy (CP) is a common pediatric disorder occurring in approximately $2-2.5$ per 1000 live births. ${ }^{1}$ It is a chronic motor disorder resulting from a non-progressive (static) insult to the developing brain. ${ }^{2}$ The motor disorders associated with CP are often accompanied by disturbances in coordination, cognition, communication, and seizure disorders., Children with CP are at increased risk of developing dental problems as compared with healthy controls. ${ }^{5}$ This can create significant morbidity that can further affect the wellbeing of these compromised children and negatively impact their quality of life. ${ }^{6}$ Screening for these conditions should be part of the initial assessment. The objectives of this article are to present an updated overview of dental health issues in children with CP and outline important preventative and practical strategies to the management of this common comorbidity.

Predisposition to dental disease in CP. Studies have shown that the more severe the neurological insult in children with CP, the higher is the risk of dental disease. ${ }^{7,8}$ This results from multiple factors including motor and coordination difficulties, as well as limited oral care and hygiene. Various possible predisposing factors are summarized in Table 1 . These include mental retardation, which is more common in children with severe CP particularly in those with epilepsy or cortical abnormalities on neuroimaging. ${ }^{9}$ Children with mental retardation are dependent on their caregiver for maintaining oral and dental hygiene making them at higher risk for dental disease. In addition, approximately $30 \%$ of CP patients are undernourished,

Disclosure. The authors declare no conflicting interests, support or funding from any drug company. 
Table 1 - Factors possibly predisposing to dental disease in children with cerebral palsy.

\begin{tabular}{lc}
\hline Predisposing factors & Mechanism \\
\hline Motor weakness or incoordination & Inability to maintain oral hygiene \\
Mental retardation & Depending on a caregiver for self care risk of dental trauma \\
& Inability to maintain oral hygiene \\
Pseudo-bulbar palsy & Depending on a caregiver for self care \\
& Chewing and swallowing difficulties \\
& Risk of dental caries and erosions \\
Gastroesophageal reflux disease & Excessive drooling (sialorrhea) \\
Malnutrition & Recurrent regurgitation and vomiting causing dental erosions \\
& Poor calcium intake \\
& Vitamin D deficiency \\
\hline
\end{tabular}

affecting their dental health. ${ }^{10}$ The leading cause of poor nutrition appears to be pseudo-bulbar palsy, affecting the coordination of sucking, chewing, and swallowing. Excessive drooling (sialorrhea) also results from pseudo-bulbar palsy, however, it may also be related to increased production of saliva secondary to an irritating oral lesion, such as dental caries or infection. ${ }^{11}$ In addition, gastroesophageal reflux disease (GERD) is another common problem in children with CP causing regurgitation, vomiting, and possible aspiration. ${ }^{12}$ The GERD affects the dental health and results in dental erosions. ${ }^{13}$

Specific dental manifestations: Dental Caries. In general, many factors contribute to the development of dental caries including biological, economic, cultural, environmental and social factors. ${ }^{14}$ Patients with $\mathrm{CP}$ are at increased risk of developing dental caries affecting negatively their quality of life. ${ }^{15}$ Children with more severe neurological insult are at a greater the risk. ${ }^{16}$ The degree of cognitive and motor deficits is directly proportional to the likelihood of developing dental caries. ${ }^{17}$ Severe motor incoordination affects the ability to perform adequate oral hygiene and cognitive deficits makes cooperation for effective oral care more difficult. ${ }^{18}$

Periodontal disease. Several studies have shown that gingival hyperplasia and associated bleeding occurs with higher frequency in children with CP. ${ }^{19,20}$ This high frequency may be due to the same factors predisposing to dental caries and leading to biofilm buildup. ${ }^{21}$ Difficulties in conducting daily oral hygiene, intraoral sensitivity, and oro-facial motor dysfunction are the main contributing factors. ${ }^{22}$ Another important factor is the use of antiepileptic drugs, particularly phenytoin. ${ }^{23}$ Gingival hyperplasia is predictive for periodontal diseases. It tends to occur in children with spastic quadriplegic $\mathrm{CP}$, particularly with advancing age. Choreothetoid CP may also be associated with periodontal disease as a result of the continuous uncontrolled movements of the head making oral hygiene more difficult. ${ }^{24}$

Dental erosion. Dental erosion is a progressive loss of hard dental tissue resulting from a chemical (nonbacterial) process. ${ }^{25}$ Gastroesophageal reflux disease is the single most important cause of dental erosions noted in up to $55 \%$ of patients. ${ }^{26}$ In one study, $75 \%$ of children with reflux on a 24 -hour esophageal $\mathrm{pH}$ monitoring had moderate to severe erosion. ${ }^{27}$ Dental erosion is common in patients with CP who are predisposed to GERD. Another study found $73 \%$ of CP patients with dental erosions had history of GERD.$^{28}$ Swallowing difficulties and recurrent chest infections were associated with the development of dental erosion in another study. ${ }^{29}$ Enamel erosion that affects the posterior dentition may be the first indication of GERD. However, both primary and permanent teeth can be affected, most commonly the upper molars, lower molars and upper incisors. Continuous chemical exposure may gradually result in the extension of the dental erosions. Early effective treatment of GERD is critical to avoid irreversible dental damage. ${ }^{30}$ Prevention, early identification, and intervention are needed to prevent permanent damage.

Sialorrhea. Drooling of saliva (sialorrhea) appears to be the consequence of a dysfunction in the coordination of swallowing mechanisms (pseudobulbar palsy) and mouth opening. Drooling is not socially accepted and can produce significant negative effects on the psychosocial health and quality of life. ${ }^{31} \mathrm{It}$ occurs in up to $30 \%$ of children with $\mathrm{CP}^{32}$ Sometimes drooling is related to an irritating lesion, such as dental caries or throat infection, resulting in increased production of saliva. Severe drooling may get worse with some antiepileptic drugs, such as clonazepam, leading to aspiration syndrome, skin irritation, and articulation difficulties. ${ }^{32}$ Management of this difficult 
problem is not very effective and includes a trial of an anticholinergic medication, such as glycopyrrolate and scopolamine. Side effects include irritability, sedation, blurred vision, and constipation. ${ }^{33}$ Scopolamine is also available as a skin patch. Surgical re-routing of salivary ducts is an option, however, it may lead to increased aspiration. ${ }^{33}$ Botulinum toxin injection into the parotid and submandibular glands may be effective in reducing excessive drooling. ${ }^{34}$

Bruxism. Bruxism, the habitual grinding of teeth, is a common problem in children with CP, particularly those with severe motor and cognitive deficits. ${ }^{35}$ Bruxism may lead to teeth abrasion and flattening of biting surfaces. The exact mechanisms causing the development of this habit is not fully known, however, it is likely a self-stimulatory behavior and could also be related to abnormal proprioception in the periodontium. ${ }^{36}$ It is known that children with $\mathrm{CP}$ are predisposed to such abnormal behaviors including finger sucking and other mouthing habits. Local dental factors, such as malocclusion, should be excluded. As well, sleep disorders may predispose to the development of nocturnal bruxism, particularly in those with severe visual impairment. ${ }^{37}$ Disturbed and fragmented sleep is very disruptive to the parents as a result of frequent nocturnal awakenings. Medications that improve the sleep-wake cycle, such as melatonin, should be used and may also result in improved daytime behavior. ${ }^{37}$

Traumatic dental injuries. Motor deficits and epilepsy increase the risk of physical injuries in children with CP. Malocclusion with prominent maxillary incisors and incompetent lips represent local risks that further predisposing to dental trauma. ${ }^{38}$ The risk varies between $10-20 \%$ and can reach $60 \%$ in patients with drop attacks. ${ }^{39}$ In addition to facial injury, these children are predisposed to fracture of enamel and dentine. ${ }^{40}$

Malocclusion. Malocclusion has been reported with increasing frequency in children with $\mathrm{CP}$, most commonly over-bite and anterior open-bite. ${ }^{41}$ These abnormalities have been reported to get worse with age. ${ }^{42}$ Mouth breathing, lip incompetence and long face are contributing factors. ${ }^{43}$ Pseudo-bulbar palsy, oro-facial incoordination and hypotonia could further add to the risk of developing malocclusion.

Enamel defects. Children with CP are at an increased risk for having developmental enamel defects. ${ }^{44}$ Around $40 \%$ of affected children were born prematurely (<37 weeks). These enamel defects are located in a symmetrical manner in both primary incisors and first molars.
Temporomandibularjoint (TMJ) disorders. Children with CP are at a significantly higher risk for developing signs and symptoms of TMJ disorders. ${ }^{45}$ Male gender, the presence and severity of any malocclusion, mouth breathing, and mixed dentition were all identified as risk factors for developing signs and symptoms of TMJ disorders in CP patients.

Dental management. Some practical challenges are commonly encountered when handling children with CP. These include apprehension, fear from strangers, and communication difficulties. ${ }^{46}$ Effective communication with such children during dental assessment should take in consideration their developmental age and any associated auditory, visual or speech disorders. Cognitive and attention deficits can also contribute to cooperation difficulties. Special seating and positioning adjustments are needed for children with abnormal posture. The dental chair should allow careful adjustment to provide the needed stability and support. Tipping the chair well back is often needed in spastic and athetoid CP patients with more manual control. Supportive and relaxed approach can help in improving the child's cooperation. ${ }^{46}$ A useful tip is to schedule the visit early in the day and allow sufficient time to establish appropriate interaction during such encounters. ${ }^{47}$ The dentist may not establish much during the first visit that may be used mainly to establish mutual confidence and have a preliminary assessment. Assistance from the parents and dental assistant is often needed particularly for immobilization and during X-ray procedures. Patients with more severe spasticity involving the head and neck may be best evaluated on the parent's lap. ${ }^{48}$ Head position can be also maintained in the midline by the help of Velcro straps. Open mouth can be maintained with the use of mouth props and the dentist should try their best to be gentle, caring, and avoid sudden movements that may trigger muscle spasm or stiffening. A finger guard and a steel mirror are preferred to avoid injury or shattering. Sharp instruments should be used with extreme caution to prevent injury. There are no reservations on using local anesthesia. CP patients often have difficulty rinsing appropriately necessitating the provision of water spray and suction device. Orthodontic or prosthetic parts are advisable only if the disability is mild to minimize the risk of breakage and aspiration.

Sedation \& anesthesia. Children with CP may be difficult to handle and uncooperative during dental assessment and management. Sedation and anesthesia is frequently needed in such situations, particularly if invasive procedures are needed. ${ }^{49}$ History of respiratory difficulties and seizures represent a particular challenge. 
Assessment by the concerned specialty (pediatrics, anesthesia, and/or neurology) is often needed prior to the required procedure. If the procedure is associated with prolonged period of decreased oral intake, intravenous antiepileptic drugs can replace the oral medications. Drugs like phenobarbitone or phenytoin can be used, however, a loading dose should be initiated before the procedure for optimal effects. ${ }^{50}$ Once the patient is able to take the oral drugs, IV drugs can be weaned quickly.

Many drugs can be used to induce sedation and anesthesia including benzodiazepines, nitrous oxide, narcotics, and propofol. ${ }^{51}$ Most children with CP and severe mental disability do not tolerate initial facemask prior to IV sedation. However, nasal or facemask can be utilized in milder cases to avoid the fear and anxiety associated with IV insertion. Oxygen saturation should be monitored by pulse oximetry and the airway should be protected throughout the procedure. Children with CP are at an increased risk of aspirating dental filling materials, debris from preparation of the tooth, or even an extracted tooth. This is in addition to excessive salivation and water spray used for cooling instruments. ${ }^{51} \mathrm{~A}$ throat shield should always be used to further protect the airway in these cases. Postoperative care include keeping the child with CP restrained until he or she is able to respond to verbal commands or become fully consciousness. IV cannulas and monitor should be removed as soon as possible as they add to the child's fear and anxiety. Most patients with CP tolerate such procedures and sedation well with minimal postoperative complications. ${ }^{52}$

Prevention. Home dental care and hygiene should be promoted from early on. Parents should learn to start gently daily cleansing of the incisors with a soft cloth or an infant soft toothbrush. For older children who are unwilling or physically unable to cooperate, the dentist should teach the parent proper brushing techniques and ways to safely restrain the child when necessary. The child is placed in the parent's lap to stabilized the head with one hand while using the other hand to brush the teeth. An older child may recline on a chair or bed and the parent angles the head backward with one hand while the teeth are brushed with the other hand. More extreme restraining by both parents is needed for the more difficult child. ${ }^{53}$ The patient's hands may have to be restrained by a second or third person for effective oral cleansing. ${ }^{53}$ To encourage independence of children with milder motor disabilities, an electric toothbrush may be utilized effectively.

In conclusions, as oral health is increasingly recognized as a foundation for general wellbeing, caregivers for CP patients should be considered an important component of the oral health team and must become knowledgeable and competent in home oral health practices. Such practices can significantly affect the child's quality of life and control dental costs.

\section{References}

1. Bax M, Goldstein M, Rosebaum P, Leviton A, Paneth N, Dan B, et al. Proposed definition and classification of cerebral palsy, April 2005. Dev Med Child Neurol 2005; 47: 571-576.

2. Jan MM. Cerebral palsy: comprehensive review and update. Ann Saudi Med 2006; 26: 123-132.

3. Rosenbaum P, Stewart D. The World Health Organization International Classification of Functioning, Disability, and Health: a model to guide clinical thinking, practice and research in the field of cerebral palsy. Semin Pediatr Neurol 2004; 11 : $5-15$.

4. Gokkaya NK, Caliskan A, Karakus D, Ucan H. Relation between objectively measured growth determinants and ambulation in children with cerebral palsy. Turk J Med Sci 2009; 39: 85-90.

5. Grzić R, Bakarcić D, Prpić I, Jokić NI, Sasso A, Kovac Z, et al. Dental health and dental care in children with cerebral palsy. Coll Antropol 2011; 35: 761-764.

6. Sehrawat N, Marwaha M, Bansal K, Chopra R. Cerebral palsy: a dental update. Int J Clin Ped Dent 2014; 7: 109-118.

7. Sankar C, Mundkur N. Cerebral palsy definition, classification, etiology and early diagnosis. Indian J Pediatr 2005; 72: 865-868.

8. Jones MW, Morgan E, Shelton JE. Primary care of the child with cerebral palsy: a review of system (Part II). J Pediatr Health Care 2007; 21: 226-237.

9. Russman BS, Ashwal S. Evaluation of the child with cerebral palsy. Semin Pediatr Neurol 2004; 11: 47-57.

10. Eltumi M, Sullivan PB. Nutritional management of the disabled child: the role of percutaneous endoscopic gastrostomy. Dev Med Child Neurol 1997; 39: 66-68.

11. Siegel L, Klingbeil M. Control of drooling with transdermal scopolamine in a child with cerebral palsy. Dev Med Child Neurol 1991; 33: 1013-1014.

12. Alsaggaf AH, Jan MM, Saadah OI, Alsaggaf HM. Percutaneous endoscopic gastrostomy (PEG) tube placement in children with neurodevelopmental disabilities: parents' perspectives. Saudi Med J 2013; 34: 695-700.

13. Polat Z, Akgun OM, Turan I, Polat GG, Altun C. Evaluation of the relationship between dental erosion and scintigraphically detected gastroesophageal reflux in patients with cerebral palsy. Turk J Med Sci 2013; 43: 283-288.

14. Beck JD, Youngblood M Jr, Atkinson JC, Mauriello S, Kaste LM, Badner VM, et al. The prevalence of caries and tooth loss among participants in the Hispanic Community Health Study/ Study of Latinos. J Am Dent Assoc 2014; 145: 531-540.

15. Cardoso AM, Gomes LN, Silva CR, Soares RD, De Abreu $\mathrm{MH}$, Padilha WW, et al. Dental caries and periodontal disease in Brazilian children and adolescents with cerebral palsy. Int J Environ Res Public Health 2014; 12: 335-353.

16. Santos MT, Guare RO, Celiberti P, Siqueira WL. Caries experience in individuals with cerebral palsy in relation to oromotor dysfunction and dietary consistency. Spec Care Dentist 2009; 29: 198-203. 
17. Dourado Mda R, Andrade PM, Ramos-Jorge ML, Moreira RN, Oliveira-Ferreira F. Association between executive/attentional functions and caries in children with cerebral palsy. Res Dev Disabil 2013; 34: 2493-2499.

18. Subasi F, Mumcu G, Koksal L, Cimilli H, Bitlis D. Factors affecting oral health habits among children with cerebral palsy: pilot study. Pediatr Int 2007; 49: 853-857.

19. Minear WL. A classification of cerebral palsy. Pediatrics 1956; 18: 841-852.

20. World Health Organization. International classification of functioning (ICF), disability and health. WHO- FIC information sheet. Geneva (CH): WHO; 2010. Available from: http://www.who.int/classifications/en/

21. Graham HK, Harvey A, Rodda J, Nattrass GR, Pirpiris M. The Functional Mobility Scale (FMS). J Pediatr Orthop 2004; 24: 514-520.

22. Gunel MK, Mutlu A, Tarsuslu T, Livanelioglu A. Relationship among the Manual Ability Classification System (MACS), the Gross Motor Function Classification System (GMFCS), and the functional status (WeeFIM) in children with spastic cerebral palsy. Eur J Pediatr 2009; 168: 477-485.

23. Jan MM. Clinical review of pediatric epilepsy. Neurosciences (Riyadh) 2005; 10: 255-264.

24. Parkin SF, Hargreaves JA, Weyman J. Children's dentistry in general practice. Br Dent J 1970; 129: 27-29.

25. Barron RP, Carmichael RP, Marcon MA, Sàndor GK. Dental erosion in gastroesophageal reflux disease. J Can Dent Assoc 2003; 69: 84-89.

26. Vakil N, van Zanten SV, Kahrilas P, Dent J, Jones R; Global Consensus Group. The Montreal definition and classification of gastroesophageal reflux disease: a global evidence-based consensus. Am J Gastroenterol 2006; 101: 1900-1920; quiz 1943.

27. Shaw L, Weatherill S, Smith A. Tooth wear in children: an investigation of etiological factors in children with cerebral palsy and gastroesophageal reflux. ASDC J Dent Child 1998; 65: 484-486.

28. Su JM, Tsamtsouris A, Laskou M. Gastroesophageal reflux in children with cerebral palsy and its relationship to erosion of primary and permanent teeth. J Mass Dent Soc 2003; 52: 20-24.

29. Gonçalves GK, Carmagnani FG, Corrêa MS, Duarte DA, Santos MT. Dental erosion in cerebral palsy patients. J Dent Child (Chic) 2008; 75: 117-120.

30. Goncalves GK, Carmagnani FG, Correa MS, Duarte DA, Santos MT. Dental erosion in cerebral palsy patients. J Dent Child 2008; 75: 117-120.

31. Meningaud JP, Pitak-Arnnop P, Chikhani L, Bertrand JC. Drooling of saliva: a review of the etiology and management options. Oral Surg Oral Med Oral Pathol Oral Radiol Endod 2006; 101: 48-57.

32. Siegel L, Klingbeil M. Control of drooling with transdermal scopolamine in a child with cerebral palsy. Dev Med Child Neurol 1991; 33: 1013-1014.

33. Toder D. Respiratory problems in the adolescent with developmental delay. Adolesc Med 2000; 11: 617-631.

34. Ohito FA, Opinya GN, Wang'ombe J. Traumatic dental injuries in normal and handicapped children in Nairobi, Kenya. East Afr Med J 1992; 69: 680-682.

35. Ortega AOL, Guimaraes AS, Ciamponi AL, Marie SKN. Frequency of parafunctional oral habits in patients with cerebral palsy. J Oral Rehabil 2007; 34: 323-328.
36. Lindqvist B, Heijbel J. Bruxism in children with brain damage. Acta Odontol Scand 1974; 32: 313-319.

37. Jan MM. Melatonin for the treatment of handicapped children with severe sleep disorders. Pediatr Neurol 2000; 23: 229-232.

38. Holan G, Peretz B, Efrat J, Shapira Y. Traumatic injuries to the teeth in young individuals with cerebral palsy. Dent Traumatol 2005; 21: 65-69.

39. Al-Banji MH, Zahr DK, Jan MM. Lennox-Gastaut syndrome. Management update. Neurosciences (Riyadh) 2015; 20: 207-212.

40. dos Santos MT, Souza CB. Traumatic dental injuries in individuals with cerebral palsy. Dent Traumatol 2009; 25: 290-294.

41. Strodel BJ. The effects of spastic cerebral palsy on occlusion. ASDC J Dent Child 1987; 54: 255-260.

42. Rosenbaum $\mathrm{CH}$, McDonald RE, Levitt EE. Occlusion of cerebral-palsied children. J Dent Res 1966; 45: 1696-1700.

43. Miamoto CB, Ramos-Jorge ML, Pereira LJ, Paiva SM, Pordeus IA, Marques LS. Severity of malocclusion in patients with cerebral palsy: determinant factors. Am J Orthod Dentofacial Orthop 2010; 138: 394-395.

44. Lin X, Wu W, Zhang C, Lo EC, Chu CH, Dissanayaka WL. Prevalence and distribution of developmental enamel defects in children with cerebral palsy in Beijing, China. Int J Paediatr Dent 2011; 21: 23-28.

45. Miamoto CB, Pereira LJ, Paiva SM, Pordeus IA, Ramos-Jorge ML, Marques LS. Prevalence and risk indicators of temporomandibular disorder signs and symptoms in a pediatric population with spastic cerebral palsy. J Clin Pediatr Dent 2011; 35: 259-263.

46. Jan MM. Neurological examination of difficult and poorly cooperative children. J Child Neurol 2007; 22: 1209-1213.

47. Dean JA, Avery DR, McDonald RE, editors. Dentistry for the child and adolescents. 9th ed. Missouri (USA): Elsevier publication; 2011.

48. Santos MT, Manzano FS. Assistive stabilization based on the neurodevelopmental treatment approach for dental care in individuals with cerebral palsy. Quintessence Int 2007; 38: 681-687.

49. Wongprasartsuk P, Stevens J. Cerebral palsy and anaesthesia. Paediatr Anaesth 2002; 12: 296-303.

50. Jan MM, editor. Manual of child neurology: problem based approach to common disorders. Bentham science: UAE; 2012.

51. Solomowitz BH. Treatment of mentally disabled patients with intravenous sedation in a dental clinic outpatient setting. Dent Clin North Am 2009; 53: 231-242.

52. Loyola-Rodriguez JP, Aguilera-Morelos AA, Santos-Diaz MA, Zavala-Alonso V, Davila-Perez C, Olvera-Delgado $\mathrm{H}$, et al. Oral rehabilitation under dental general anesthesia, conscious sedation, and conventional techniques in patients affected by cerebral palsy. J Clin Pediatr Dent 2004; 28: 279-284.

53. Ferguson FS, Cinotti D. Home oral health practice: the foundation for desensitization and dental care for special needs. Dent Clin North Am 2009; 53: 375-387. 